\title{
The effects for the number of beech pollinosis patients by low temperature and a good beech harvest
}

\author{
Mayumi Fujii ${ }^{1,2 *}$, Kiyoshi Makiyama ${ }^{2}$, Kenji Okazaki ${ }^{3}$ and Kenichi Hisamatsu ${ }^{4}$ \\ ${ }^{1}$ Fujii Clinic 6-19 Ginzamotomachi, Ito-shi, Shizuoka 414-0028, Japan \\ ${ }^{2}$ Department of Otorhinolaryngology, Nihon University Hospital Chiyoda-ku, Tokyo, Japan \\ ${ }^{3}$ Okazaki Otorhinolaryngology Clinic Toshima-ku, Tokyo, Japan \\ ${ }^{4}$ Hisamatsu Otorhinolaryngology Clinic Tsuchiura-shi, Ibaraki, Japan
}

\begin{abstract}
Backgrounds: Beech pollinosis, which can cause anaphylaxis, has not been regarded as a risk and hardly studied in Japan. We think there is a risk that beech pollinosis may be a problem in the future in Japan and other countries. This study is to improve the prevention and treatment of beech pollinosis.

Results: When it was a good beech harvest and low temperature at the same time, beech pollinosis patients were likely to be increased.

Conclusions: It is necessary to pursue further study on the effects of low temperature and scattering beech pollen count for the number of beech pollinosis patients. Beech should be included in the allergen test kits including 36 or 39 allergens of National Health Insurance in Japan, which could improve the prevention and treatment of beech pollinosis.
\end{abstract}

\section{Introduction}

Beech pollinosis has so much risk that presents anaphylaxis, but research reports are few. First, we briefly describe beech pollinosis and beech characteristics.

\section{About beech pollinosis}

1. Combined food allergies, there is a risk of leading to anaphylactic shock.

2. Beech pollinosis patients are hardly counted because the allergen test kits containing 36 or 39 allergens of National Health Insurance have not included beech as an allergen in Japan.

3. Beech has common epitopes with birch.

4. The treatment is same as other pollinosis.

\section{Characteristics of beech}

1. Take toxins from the roots and inhibit the growth of other trees.

2. In Japan, besides the Shirakami Sanchi, there are large beech forests in Hakusan and Fukushima.

3. There is a seed dispersal system called mast.

3.1 A beech mast correlates with average low temperature in April and May in the previous year [1].

3.2 A beech mast is caused by annual fluctuation of nitrogen resources [2].

It is considered that beech pollinosis has not been regarded as a risk in Japan because there are few large beech forests and the patients do not exist nationwide; how is beech pollinosis reacted where people live near large beech forest then?
We asked a literature/interview survey at Shirakami Sanchi which is the largest beech forest in Japan. If there are a lot of beech pollinosis patients around Shirakami Sanchi, there should be descriptions of beech pollinosis in some literature, and there should be some note of food that induces anaphylaxis.

However, in Hirosaki Library, not far from Shirakami Sanchi, there was a description of apple pollinosis, but there was no description of beech pollinosis. And there was no one who knew beech pollinosis in interview survey in Sirakami Sanchi.

Beech pollinosis might be difficult to be onset. Be that as it may, as there are the patients, there should be a mechanism of onset. We make the following hypothesis from the relationship between a beech mast and weather. In Hokkaido type beech case, it is a good harvest when the temperature in April and May in the previous year is low[1]. If a good harvest year goes on, when it is a good harvest and low temperature at the same time, with one's weakened immune system, beech pollinosis patients increase.

However, it is not known whether the correlation between a beech mast and weather is applicable in Honshu. Neither is it known whether beech pollinosis would be easy to onset when it is a good beech harvest and it has a lower temperature than usual at the same time.

Correspondence to: Mayumi Fujii, Fujii Clinic 6-19 Ginzamotomachi, Ito-shi, Shizuoka 414-0028; Department of Otorhinolaryngology, Nihon University Hospital Chiyoda-ku, Tokyo, Japan, Tel. 0557-35-2000; Fax: 0557-35-2007; E-mail:mfujii@crux.ocn.ne.jp

Key words: beech, Fagaceae, pollinosis, mast

Received: March 03, 2018; Accepted: March 09, 2018; Published: March 12 , 2018 
We investigated whether the correlation between a beech mast and low temperature can be applied at Ito in Honshu, whether beech pollinosis patients increase when it is a good beech harvest and low temperature.

\section{Materials and Methods}

We measured the number of airborne beech pollen and explore whether beech pollinosis patients will come out when the number of airborne beech pollen is high and the temperature is low. 2004-2017 in Ito City Shizuoka, near the beech forest of Mt. Amagi, airborne beech pollen was measured by a Durham sampler. Ikuse's pollen diagram was applied [3] .

Weather information by the Meteorological Agency is used; the data at Ajiro where is near to Ito are applied.

All the numerical values are analyzed by Microsoft Excel 2010. The standard deviations of the data are calculated with STDEVPA function. The correlations among the data are calculated with Pearson productmoment correlation coefficient. We did regression analysis between weather and beech pollen data with EZR [4].

\section{Result}

At Ito in Honshu there was no correlation between a beech mast and weather [5]. Pollen dispersion of Fagaceae from March to June at Ito during 2004 to 2017 (Table 1): year dates of initial pollen observed, of pollen release began, of final pollen observation, of maximum pollen dispersion and maximum pollen counts. Each average value and standard deviations: $7 \pm 21$-Mar, 25 \pm 8 -Mar, 14 \pm 11 -Jul, 1 \pm 9 -May and $135 \pm 95 \mathrm{grain} / \mathrm{cm}^{2}$. AWe found that the airborne pollen count of the date of maximum pollen dispersion tends to be large in the year with much total airborne pollen although there are not correlations between total airborne pollen and the date of initial pollen observed, between the date of pollen release began and the date of final pollen observation as a result of the regression analysis.

On the other hand, in 2014, when a good beech harvest year went on and average low temperature of previous April and May was extremely low, two beech pollinosis patients were found and potential beech pollinosis patients seemed increased at Fujii Clinick in Ito City. Airborne beech pollen count and weather (Table 2). Each average values and standard deviations of the amount of rainfall and average low temperature from previous April to previous May which effect on flower bud formation of the family Fagaceae, $364 \pm 123 \mathrm{~mm}$ and $12.6 \pm 1.6^{\circ} \mathrm{C}$. The average values and standard deviations of the amount of rainfall, temperature and total sunshine duration from April to June when beech pollen is scattered are $588 \pm 148 \mathrm{~mm} 17.9 \pm 1.0^{\circ} \mathrm{C}, 508 \pm 71$ hours.

The result of the regression analysis to calculate airborne pollen count of the family Fagaceae $(\mathrm{Y})$ among airborne pollen count of previous year $\left(\mathrm{X}_{1}\right)$, average low temperature from previous April to previous $\operatorname{May}\left(\mathrm{X}_{2}\right)$ and total sunshine duration from April to June $\left(\mathrm{X}_{3}\right)$ from 2005 to 2017: although there is not significant correlation among $(\mathrm{Y}),\left(\mathrm{X}_{1}\right),\left(\mathrm{X}_{2}\right)$ and $\left(\mathrm{X}_{3}\right)$ ( $\mathrm{p}$ value $\left.>10 \%\right),\left(\mathrm{X}_{3}\right)$ as a explanatory variable shows positive correlation ( $\mathrm{p}$ value $>3 \%$ ). $\mathrm{Y}=3.60 \times \mathrm{X}_{3}-69$.

\section{Discussion}

When the temperature is lower than usual and it is a good beech harvest at the same time, bearing beech pollenosis in mind, you would not miss it; people should take care of themselves then.

If the number of scattering beech pollen increases by the beech forest regeneration project etc., the number of beech pollinosis patients would also increase. Before the number of anaphylactic shock patients increases and becoming a social problem, it is necessary to study how low temperature and scattering beech pollen count triggers beech pollinosis, and it might be necessary to adjust scattering beech pollen count.

We are sorry that we could not use big data of beach pollinosis patients; it is difficult to count beech pollinosis patients because beech has not been included as an allergen in the allergen test kits including 36 or 39 allergens of National Health Insurance in Japan. We hope that beech will be included as an allergen in them, which must improve not only the researches but also the prevention and treatment of beech pollinosis.

\section{Acknowledgment}

We thank Prof. Seiichi Udagawa at the Department of Medicine, Nihon University for the advice about statistical methods, visiting Prof. Norio Sahashi at the Faculty of Science, Toho University for some advice, Naofumi Yamada: freelance writer, for the survey at Shirakami, Emiko Yamaguchi and Harumi Tsuchiya: Clinical Technologists, Misa Fujii: translator.

Table 1. Pollen dispersion of Fagaceae from March to June at Ito during 2004 to 2017.

\begin{tabular}{|c|c|c|c|c|c|}
\hline & March & April & May & June & March $\sim$ June \\
\hline 2004 & 8 & 1118 & 218 & 46 & 1390 \\
\hline 2005 & 0 & 282 & 181 & 12 & 475 \\
\hline 2006 & 6 & 233 & 259 & 17 & 515 \\
\hline 2007 & 13 & 371 & 515 & 11 & 910 \\
\hline 2008 & 0 & 434 & 255 & 21 & 710 \\
\hline 2009 & 14 & 875 & 475 & 18 & 1382 \\
\hline 2010 & 8 & 186 & 404 & 27 & 625 \\
\hline 2011 & 28 & 667 & 1178 & 34 & 1907 \\
\hline 2012 & 14 & 140 & 440 & 23 & 617 \\
\hline 2013 & 23 & 933 & 447 & 23 & 1426 \\
\hline 2014 & 24 & 766 & 993 & 45 & 1828 \\
\hline 2015 & 14 & 786 & 361 & 10 & 1171 \\
\hline 2016 & 9 & 636 & 475 & 23 & 1143 \\
\hline 2017 & 4 & 657 & 973 & 29 & 1663 \\
\hline mean & 12 & 577 & 512 & 24 & 1126 \\
\hline S.D. & \pm 8 & \pm 254 & \pm 289 & \pm 9 & \pm 468 \\
\hline
\end{tabular}

Pollen count $/ \mathrm{cm} 2$ 
Fujii M (2018) The effects for the number of beech pollinosis patients by low temperature and a good beech harvest

Table 2. Pollen dispersion of Fagaceae, Climate and correlation coefficient at Ito during 2004 to 2017.

\begin{tabular}{|c|c|c|c|c|c|c|}
\hline & \multirow{2}{*}{$\begin{array}{c}\text { Total pollen } \\
\text { count }^{4)} \\
\left.\text { (grain } / \mathbf{c m}^{2}\right) \\
\end{array}$} & \multirow{2}{*}{$\begin{array}{l}\text { Average low temperature } \\
\left({ }^{\circ} \mathrm{C}\right) \text { of previous April } \\
\text { and May }\end{array}$} & \multirow{2}{*}{$\begin{array}{c}\text { Amount of rainfall (mm) } \\
\text { during previous April } \\
\text { and May }\end{array}$} & \multirow{2}{*}{$\begin{array}{l}\text { Average temperature }\left({ }^{\circ} \mathrm{C}\right) \\
\text { of April, May and June }\end{array}$} & \multirow{2}{*}{$\begin{array}{l}\text { Amount of rainfall (mm) } \\
\text { during April and June }\end{array}$} & \multirow{2}{*}{$\begin{array}{l}\text { Total sunshine duration } \\
\text { during April and June (h) }\end{array}$} \\
\hline & & & & & & \\
\hline & $\mathrm{Y}$ & $\mathrm{X} 2$ & & & & $\mathrm{X} 3$ \\
\hline 2004 & 1388 & 13.2 & 311.5 & 19.2 & 621 & 504 \\
\hline 2005 & 483 & 13.7 & 221 & 18.1 & 445.5 & 539 \\
\hline 2006 & 508 & 12.4 & 340 & 17.6 & 533.5 & 352 \\
\hline 2007 & 910 & 12.6 & 265 & 14.7 & 425.5 & 570 \\
\hline 2008 & 710 & 12.4 & 580 & 17.5 & 981 & 403 \\
\hline 2009 & 1383 & 13.2 & 233.5 & 18.7 & 521.5 & 508 \\
\hline 2010 & 625 & 13.9 & 543 & 17.7 & 686.5 & 453 \\
\hline 2011 & 1908 & 12.1 & 460.5 & 18.2 & 624.5 & 508 \\
\hline 2012 & 617 & 12.4 & 510 & 17.5 & 803 & 465 \\
\hline 2013 & 1432 & 13.0 & 510 & 18.2 & 499 & 522 \\
\hline 2014 & 1828 & 7.4 & 302 & 18.2 & 572 & 599 \\
\hline 2015 & 1171 & 12.6 & 267.5 & 18.5 & 509 & 486 \\
\hline 2016 & 1143 & 13.8 & 258 & 18.8 & 574.5 & 614 \\
\hline 2017 & 1663 & 14.0 & 292.5 & 18.3 & 430 & 583 \\
\hline mean & 1126 & 12.6 & 364 & 17.9 & 588 & 508 \\
\hline s.d. & \pm 474 & \pm 1.6 & \pm 123 & \pm 1.0 & \pm 148 & \pm 71 \\
\hline \multicolumn{2}{|c|}{ correlation coefficient } & -0.37 & -0.17 & 0.38 & -0.28 & 0.56 \\
\hline
\end{tabular}

Seasonal total pollen count release began to final pollen observation. The pollen counts of masting year are colored gray.

\section{References}

1. Hirokazu Kon (2009) Evolutionary advantages and proximate factors of mast seeding in Fagus crenata. Hokkaido Forestry Research Institute 46: 53-83.

2. Abe T, Tachiki Y, Kon H, Nagasaka A, Onodera K, et al. (2016) Parameterization and validation of a resource budget model for masting using spatiotemporal flowering data of individual trees. Ecology Letters.
3. Jun Nagano, Sankei Nishima, Reiko Kishikawa, Norio Sahashi, Toshitaka Yokoyama (1992) Nihonrettou no Kuuchuukafun II (Airborne pollen of Japanese Islands) Hokuryukan 12-13

4. Kanda K (2013) Investigation of the freely available easy-to-use software 'EZR'for medical statistics. Bone Marrow Transplant 48: 452-458. [Crossref]

5. Fujii M, Okazaki K, Makiyama K, Hisamatsu K (2013) Tree pollen dispersion in Ito City, Shizuoka Prefecture. Arerugi 62: 1522-1533. [Crossref]

Copyright: $@ 2018$ Fujii M. This is an open-access article distributed under the terms of the Creative Commons Attribution License, which permits unrestricted use, distribution, and reproduction in any medium, provided the original author and source are credited. 